\title{
Application of Smart Bats Algorithm for Optimal Design of Power Stabilizer System at Sengkang Power Plant
}

\author{
Muhammad Ruswandi Djalal ${ }^{\mathrm{a}, 1}$, Herman Nawir ${ }^{\mathrm{a}, 2}$, Muhammad Yusuf Yunus ${ }^{\mathrm{a}, 3}$, Andi Imran ${ }^{\mathrm{b}, 4}$ \\ ${ }^{a}$ Department of Energy Engineering, State Polytechnic of Ujung Pandang, 90245 Makassar, Indonesia \\ ${ }^{b}$ Department of Electrical Engineering, Sepuluh Nopember Institute of Technology, Surabaya, Indonesia

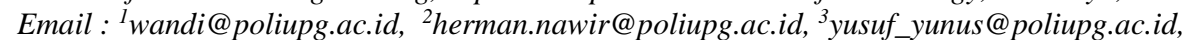 \\ ${ }^{4}$ andi.imran13@mhs.ee.its.ac.id
}

\section{ARTICLE INFO}

Article history:

Received : 09/12/2017

Revised : 10/03/2017

Accepted : 10/05/2017

\section{Keywords:}

Power System Stabilizer

Bat Algorithm

Speed

Overshoot

Settling Time

\section{ABSTRACT}

The problem of using Power System Stabilizer (PSS) in generator excitation is how to determine the optimal PSS parameter. To overcome these problems, the authors use a method of intelligent bats based algorithm to design PSS. Bat Algorithm is an algorithm that works based on bat behavior in search of food source. Correlation with this research is, food sources sought by bats represent as PSS parameters to be optimized. Bat's algorithm will work based on a specified destination function, namely Integral Time Absolute Error (ITAE). In this research will be seen the deviation of velocity and rotor angle of each generator, in case of disturbance in bakaru generator. The analysis results show that the uncontrolled system produces a large overshoot oscillation, and after the addition of PSS oscillation control equipment can be muted. So that the overshoot and settling time of each generator can be reduced and the generator can quickly go to steady state condition.

Copyright $\odot 2017$ International Journal of Artificial Intelegence Research. All rights reserved.

\section{Introduction}

Most of the power system controller functions are in the governor and exciter in each generator. However, the limited performance of the control equipment, causing the generator can not work optimally. Additional Power System Stabilizer (PSS) controller is also added to the automatic voltage regulator (AVR), the function of the eksiter, governor and PSS is to set the frequency and terminal voltage locally or globally on each generator. Load changes that occur suddenly and periodically can not be responded well by the generator so that it can affect the system dynamic stability. Inadequate response can cause oscillation of frequency in long period. This can result in a reduction in the power transfer power that can be overcome using additional equipment called PSS.

The stability of the existing power system generally consists of steady state stability and transient stability. Transient stability is associated with a sudden large interruption, such as short circuit interruptions, channel shutdown, removal or disconnection of the system. As for steady state stability associated with the ability of the power system to return to its operating point after a minor disturbance occurs. The system parameter is said to be stable if all variables are stable, system frequency, bus voltage, or generator angle. While the parameters for the instability of the system such as the voltage on some buses fall drastically far from normal conditions so as to enable the failure of the voltage.

Bakaru hydroelectric power system (PLTA Bakaru) is one of the largest plant in $150 \mathrm{kV}$ Sulselrabar system. The magnitude of the influence of PLTA Bakaru cause many dynamics that often occur, especially when the system is in disturbance. Required some studies of electrical system in Sulselrabar, along with increasing system in sulselrabar. Several studies have been conducted for the Sulselrabar system, among others [1], [2], [3]. Study Stability of electric power system is important to maintain system reliability. Artificial intelligence method is one method that is widely used in power systems. In the 
stability study of power system in sulselrabar system, intelligent method application has been started. Smart method based on Bat Algorithm is an algorithm that works based on bat behavior in search of food. Correlation with this research is Bat Algorithm will look for optimal parameter of PSS by using specified objective function, that is minimize Integral Time Absolute Error (ITAE). Some research-based smart methods for tuning include, firefly [4], Particle Swarm Optimization [5], Genetic Algorithm [6], Neural Network [7], Fuzzy Logic [8], Ant Colony [9], Bee Colony [10], Cuckoo Search [11]. Therefore, this research will be proposed Bat-Algorithm based intelligent method for designing PSS in hydroelectric power of bakaru.

\section{Power System Modeling}

After the next power flow study, the power system is modeled into a multimetin linear model in the form of a d-q model. The system model is displayed using the simulink program in Matlab and analyzed with $\mathrm{M}$. Matlab usage. Figure 1 shows the modeling of the generator with the addition of a PSS controller in the excitation generator. Figure 2 shows the conversion of $d-q$ model. Figure 3 shows the transmission modeling. Figure 4 shows the PSS modeling.

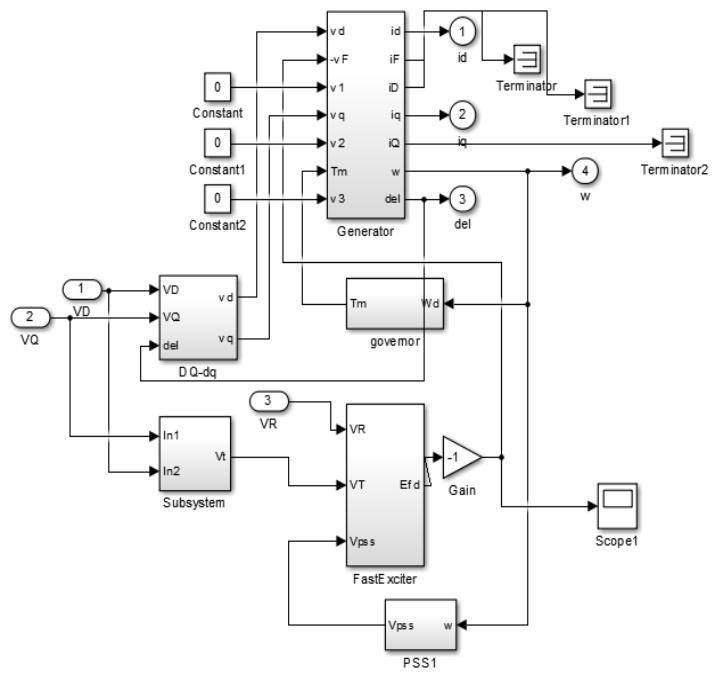

Figure 1. Generator Modeling

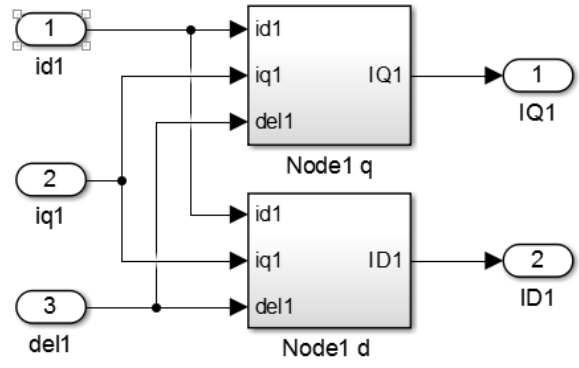

Figure 2. DQ Conversion
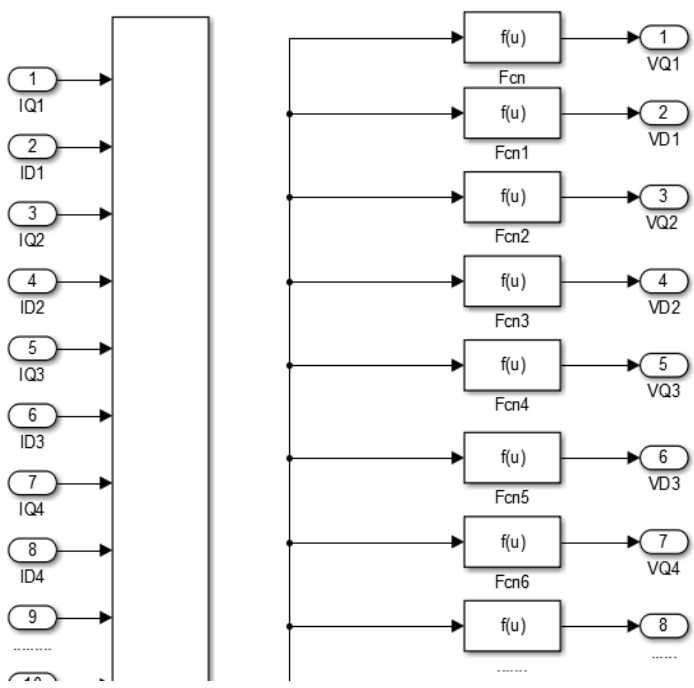

Figure 3. Transmission Modeling

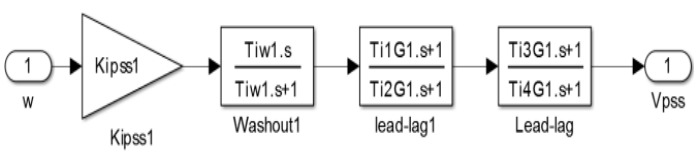

Figure 4. Power System Stabilizer Modeling

\section{Reduction of Net Admittance Matrix}

The reduction of power system nets is used to simplify the network system's admittance matrix. The goal is to reduce the admittance matrix or to eliminate the load bus, so that later this matrix size is equal to the number of generators. This reduction matrix is used in multimode power net mesh modeling. The $37 \times 37$ matrix ( 37 buses) is reduced to a $16 \times 16$ matrix (16 generators).

\section{Bats Algorithm}

The main step of BA is to start from the initialization of a population of bats set each of which is determined by the initial position as the initial solution. The population of bats generates pulses and noise at random and determines the frequency. During the process 
of repetitive / looping bats will move from the initial solution to the best solution. After moving, if any bats find a better solution, then the bat will update the level of pulse emission and noise. During the iteration process the best solution is always updated. The iteration process is repeated until the stop criteria and the best solution criteria are met. The best solution is the solution to the problems solved by the process of this algorithm. Picture is Flow Chart Bat Algorithm.

The Bat Algorithm parameters used are shown in the following table. Bat's working principle is to optimize the parameters of PSS within a given range. Bat Parameters are shown in the following table. The PSS parameters that are tuned are KPSS, T1, T2, $\mathrm{T} 3$ and T4. The value of TW has a value in the rank of $1-50 \mathrm{sec}$ limit, in TW research fixed constant is 10 seconds. Here are the parameters of Bat and PSS parameters that have been set.

Table 1. Bat Algorithm Parameter

\begin{tabular}{lc}
\hline \multicolumn{1}{c}{ Parameter } & Values \\
\hline Population Size & 35 \\
Loudness & 0,25 \\
Pulse Rate & 0,5 \\
Alpha & 0,7 \\
Gamma & 0,7 \\
Minimum Frequency & 0 \\
Maximum Frequency & 100 \\
Iteration & 50 \\
Dimention & 80 \\
\hline
\end{tabular}

Table 2. Limitation of Parameter Value of PSS

\begin{tabular}{cccc}
\hline No & Parameter & Lower Limit & $\begin{array}{c}\text { Upper } \\
\text { Limit }\end{array}$ \\
\hline 1 & $\mathrm{~K}_{\mathrm{pss}}$ & 10 & 50 \\
2 & $\mathrm{~T}_{1}$ & 0 & 0.1 \\
3 & $\mathrm{~T}_{2}$ & 0 & 0.1 \\
4 & $\mathrm{~T}_{3}$ & 0 & 5 \\
5 & $\mathrm{~T}_{4}$ & 0 & 5 \\
\hline
\end{tabular}

for parameter Tw set at value 10 .

\section{Results and Discussion}

The Sulselrabar electricity system consists of 16 generating units, operating at a voltage of $150 \mathrm{kV}$, and consists of 37 Buses and 46 channels connecting large load centers such as Makassar, Pangkep, Maros, Barru, Pare-Pare, Pinrang, Polmas, Majene and Mamuju. The objective function (Objective Function) used is to maximize minimum damping $\left(\zeta_{\min }\right)$.

Further analyzed system response is Speed Deviation $(\Delta \omega)$ and rotor angle of bakaru generator. In addition it will also be analyzed overshoot value from generator bakaru, respectively for system without control and with PSS. Linear system modeling is given input interruption input load change of 0.05 pu at Generator Slack PLTA Bakaru. Because of this load change, it causes changes in the load side causing $\mathrm{Pm}<\mathrm{Pe}$, then $\omega$ and $\delta$ of the generator will drop.

$$
M \dot{W}=P_{m}-P_{e}-D \omega
$$

\section{Load Flow}

After making sulselrabar system modeling and entering the system data, then next will do the power flow study to know the magnitude profile and phase angle of each bus, the result is shown in following table.

Table 3. Magnitude and Angle of Voltage

\begin{tabular}{cccccc}
\hline Bus & $\begin{array}{c}\text { Voltage } \\
(\mathbf{p . u})\end{array}$ & Angle $\left(^{\mathbf{0}}\right)$ & Bus & $\begin{array}{c}\text { Voltage } \\
(\mathbf{p . u})\end{array}$ & Angle $\left(^{\mathbf{0}}\right)$ \\
\hline 1 & 1,000 & 0.000 & 20 & 0,979 & -16.450 \\
2 & 1,000 & -3.869 & 21 & 0,983 & -18.428 \\
3 & 1,000 & -5.124 & 22 & 0,987 & -21.176 \\
4 & 1,000 & -4.041 & 23 & 0,960 & -23.033 \\
5 & 1,000 & -9.839 & 24 & 0,993 & -20.956 \\
6 & 1,000 & -20.793 & 25 & 0,994 & -19.485 \\
7 & 1,000 & -21.192 & 26 & 0,994 & -18.453 \\
8 & 1,000 & -20.221 & 27 & 0,990 & -8.949 \\
9 & 1,000 & -16.359 & 28 & 0,992 & -4.600 \\
10 & 1,000 & -13.152 & 29 & 0,992 & -17.723 \\
11 & 1,000 & -11.792 & 30 & 0,960 & -16.091 \\
12 & 1,000 & -2.500 & 31 & 0,933 & -17.110 \\
13 & 1,000 & 2.915 & 32 & 0,980 & -21.261 \\
14 & 1,000 & -11.380 & 33 & 0,984 & -21.251 \\
15 & 1,000 & -13.389 & 34 & 0,993 & -20.728 \\
16 & 1,000 & -20.966 & 35 & 0,996 & -20.760 \\
17 & 0,992 & -3.072 & 36 & 0,996 & -20.760 \\
18 & 0,974 & -5.217 & 37 & 0,975 & -22.476 \\
19 & 0,965 & -6.386 & & & \\
\hline
\end{tabular}

\section{Convergence of Bats Algorithm}

Here is the result of PSS parameter search convergence with bats algorithm. Where seen from the graph, the algorithm is very fast in finding the optimal value of PSS by using the method of bats algorithm. The fitness function value is 75.8423783057539 . 


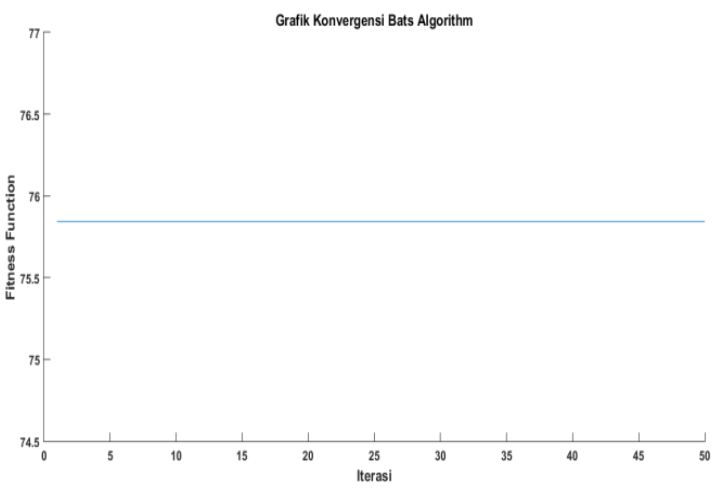

Figure 5. Convergence Graph of Bats Algorithm

Table 4. Results of PSS Parameter Optimization

\begin{tabular}{cccccc}
\hline Place & Kpss & T1 & T2 & T3 & T4 \\
\hline G1 & 38.6483 & 0.0243 & 0.0277 & 0.7740 & 1.8598 \\
G2 & 17.4338 & 0.0153 & 0.0109 & 0.7200 & 0.7924 \\
G3 & 25.4147 & 0.0199 & 0.0385 & 0.6569 & 0.9760 \\
G4 & 39.4503 & 0.0266 & 0.0117 & 0.6089 & 0.8877 \\
G5 & 44.0828 & 0.0284 & 0.0146 & 0.7818 & 1.2816 \\
G6 & 22.7142 & 0.0121 & 0.0200 & 0.1736 & 1.5760 \\
G7 & 43.2428 & 0.0169 & 0.0292 & 0.3854 & 0.3583 \\
G8 & 24.2463 & 0.0247 & 0.0256 & 0.4864 & 1.2950 \\
G9 & 23.6196 & 0.0183 & 0.0389 & 0.6131 & 1.0097 \\
G10 & 38.4322 & 0.0240 & 0.0104 & 0.4420 & 1.1055 \\
G11 & 26.9241 & 0.0174 & 0.0300 & 0.5450 & 1.4509 \\
G12 & 22.9460 & 0.0335 & 0.0223 & 0.5855 & 0.5511 \\
G13 & 41.4692 & 0.0131 & 0.0118 & 0.5147 & 1.4662 \\
G14 & 34.2208 & 0.0125 & 0.0213 & 0.3378 & 1.1100 \\
G15 & 32.0660 & 0.0155 & 0.0292 & 0.5649 & 0.3631 \\
G16 & 35.8701 & 0.0192 & 0.0160 & 0.3487 & 0.7889 \\
\hline
\end{tabular}

Installation of PSS is done on Generator Bakaru, Pinrang, Pare - Pare, Suppa, Barru, Tello, Tello lama, Sungguminasa, Bulukumba, Sinjai, Soppeng, Sengkang, Makale, and Palopo.

\section{Results and Discussions}

After placing and tuning PSS with 14 PSS placement locations, then see the response of Speed Deviation $(\Delta \omega)$ and rotor angle of each generator. Overshoot Deviation The speed of the generator will be analyzed differently. The table shows the overshoot comparison of the speed deviation of each generator.

Table 5. Overshoot Speed Deviation Generator

\begin{tabular}{ccc}
\hline Generator & No PSS & PSS Bat \\
\hline Bakaru & $-0.02563 \& 0.004704$ & $-0.01598 \& 9.635 \mathrm{e}-05$ \\
Pinrang & $-0.02385 \& 0.006865$ & $-0.01595 \& 0.0002214$ \\
Pare & $-0.02424 \& 0.004796$ & $-0.01638 \& 0.0001162$ \\
Suppa & $-0.02437 \& 0.006517$ & $-0.01435 \& 3.279 \mathrm{e}-05$ \\
Barru & $-0.08467 \& 0.03666$ & $-0.03627 \& 0.0001224$ \\
Tello & $-0.2119 \& 0.05488$ & $-0.2027 \& 0.04589$ \\
Tello lama & $-0.2227 \& 0.09127$ & $-0.07708 \& 0.000385$ \\
Sgmnsa & $-0.05721 \& 0.007811$ & $-0.03956 \& 3.942 \mathrm{e}-05$ \\
Jeneponto & $-0.02519 \& 0.006135$ & $-0.01823 \& 0.0003905$ \\
Bulukumba & $-0.02447 \& 0.01018$ & $-0.01709 \& 0.00227$ \\
Sinjai & $-0.0263 \& 0.01804$ & $-0.01887 \& 0.006823$ \\
Soppeng & $-0.0248 \& 0.01153$ & $-0.01627 \& 0.001527$ \\
Sengkang & $-0.02694 \& 0.005042$ & $-0.01689 \& 0.0002121$ \\
Makale & $-0.02397 \& 0.01706$ & $-0.01573 \& 0.003737$ \\
Palopo & $-0.02442 \& 0.01894$ & $-0.01528 \& 0.004266$ \\
Borongloe & $-0.06846 \& 0.01621$ & $-0.04373 \& 4.929 \mathrm{e}-05$ \\
\hline
\end{tabular}

The following figure shows the response of Speed Deviation $(\Delta \omega)$ and Variation of the rotor angle of each generator.

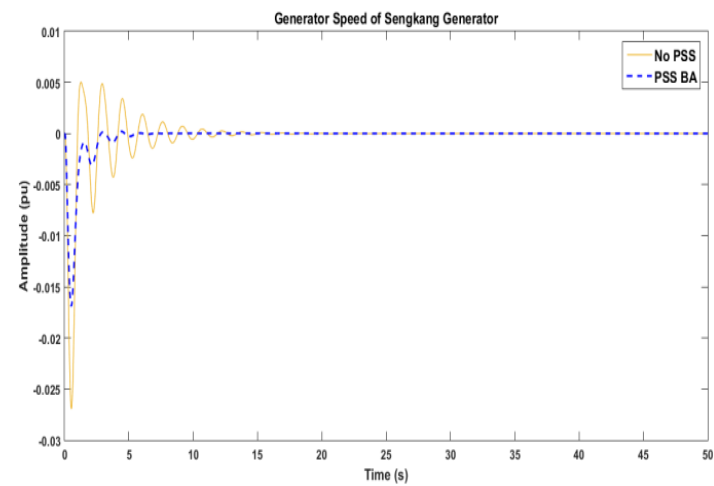

Figure 6. Speed Deviation $(\Delta \omega)$ of Sengkang Generator

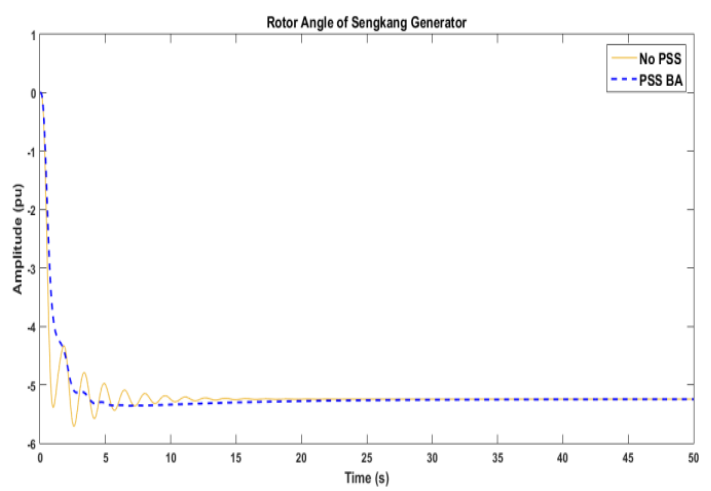

Figure 7. Angle Variation of Sengkang Generator

Figure 6 shows the generator speed response. Figure 7 shows the rotor angle deviation response of the generator, respectively after the disturbance of the bakaru generator.

\section{Conclusion}

From the figure shows the response of the Speed Deviation $(\Delta \omega)$ and the rotor angle of the generator of the stirrup, when there is a disturbance in this case is disturbed in the generator of the bakaru, and from the deviation graph of the velocity can be seen the overshoot oscillation that occurs decreasing after PSS installed, ie without optimization of $-0.02694 \& 0.005042 \mathrm{pu}$, and after optimization of $-0.01689 \& 0.0002121 \mathrm{pu}$. In addition, the resulting settling time will also be faster to get to steady state conditions using the proposed method Bat Algorithm compared with the system without control.

From the analysis results can be concluded, the performance of the system performance increases with the installation of Power System Stabilizer with optimal PSS parameters. 


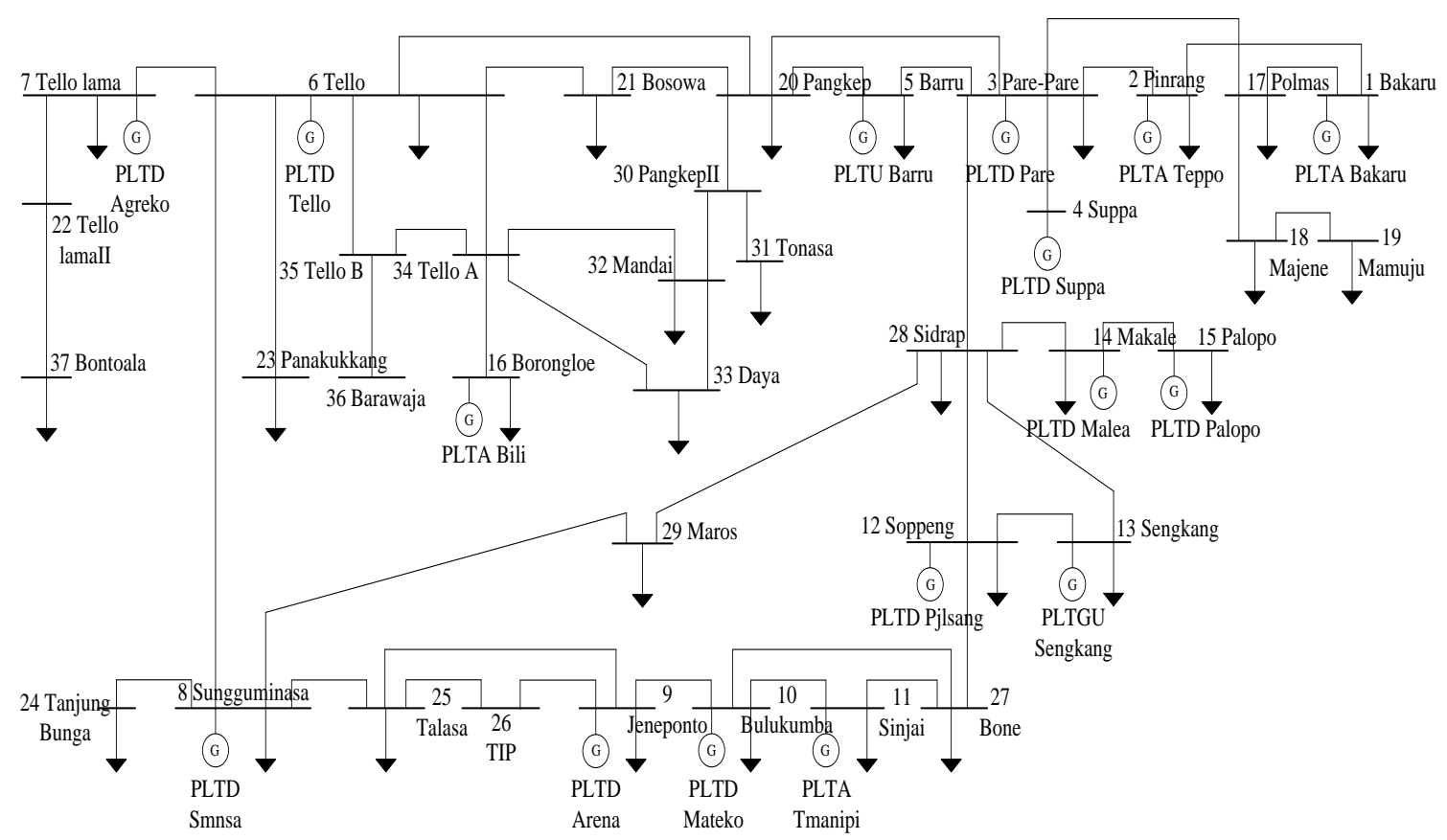

Gambar 8. Single Line Diagram of 150 kV Sulselrabar System [12]

\section{DAFTAR Pustaka}

[1] M. R. Djalal, D. Ajiatmo, A. Imran, and I. Robandi, "Desain Optimal Kontroler PID Motor DC Menggunakan Cuckoo Search Algorithm," SENTIA 2015, vol. 7, 2015.

[2] M. R. Djalal, M. A. Haikal, T. M. P. N. U. Pandang, and T. E. I. P. Aceh, "Penyelesaian Aliran Daya 37 Bus Dengan Metode Newton Raphson (Studi Kasus Sistem Interkoneksi 150 kV Sulawesi Selatan)," Jurnal Teknik Mesin SINERGI, vol. 12, pp. 35-49, 2014.

[3] M. R. Djalal, H. Nawir, H. Setiadi, and A. Imran, "An Approach Transient Stability Analysis Using Equivalent Impedance Modified in $150 \mathrm{kV}$ South of Sulawesi System," Journal of Electrical and Electronic Engineering-UMSIDA, vol. 1, pp. 1-7, 2017.

[4] A. Ameli, M. Farrokhifard, A. Ahmadifar, A. Safari, and H. A. Shayanfar, "Optimal tuning of Power System Stabilizers in a multimachine system using firefly algorithm," in 2013 12th International Conference on Environment and Electrical Engineering, 2013, pp. 461-466.

[5] H. Shayeghi, A. Safari, and H. Shayanfar, "Multimachine power system stabilizers design using PSO algorithm."

[6] K. Hongesombut, Y. Mitani, and K. Tsuji, "Power system stabilizer tuning in multimachine power system based on a minimum phase control loop method and genetic algorithm."

[7] M. Jalali, R. Pouaghababa, and M. Nouhi, "Power System Stabilizers Optimization
Based on Neural Network using linear Optimal Control."

[8] R. Syahputra and I. Soesanti, "Power System Stabilizer model based on Fuzzy-PSO for improving power system stability," in Advanced Mechatronics, Intelligent Manufacture, and Industrial Automation (ICAMIMIA), 2015 International Conference on, 2015, pp. 121-126.

[9] M. M. Linda and N. K. Nair, "Optimal design of multi-machine power system stabilizer using robust ant colony optimization technique," Transactions of the Institute of Measurement and Control, vol. 34, pp. 829840, 2012.

[10]B. S. Theja, A. Raviteja, A. Rajasekhar, and A. Abraham, "Coordinated design of power system stabilizer using thyristor controlled series compensator controller: An artificial bee colony approach," in Communication Systems and Network Technologies (CSNT), 2012 International Conference on, 2012, pp. 606-611.

[11]D. Chitara, A. Swarnkar, N. Gupta, K. Niazi, and R. Bansal, "Optimal Tuning of Multimachine Power System Stabilizer using Cuckoo Search Algorithm," IFACPapersOnLine, vol. 48, pp. 143-148, 2015.

[12] M. R. Djalal, A. Imran, and I. Robandi, "Optimal placement and tuning power system stabilizer using Participation Factor and Imperialist Competitive Algorithm in $150 \mathrm{kV}$ South of Sulawesi system," in Intelligent Technology and Its Applications (ISITIA), 2015 International Seminar on, 2015, pp. 147152. 